\title{
Improving the creation and management of collaborative networks within
}

\section{the European maritime sector}

This work was supported by the [European Commission] as a part of the Seventh Framework Programme, Coordination and support action [number SCSO-GA-2011-266054]

\section{Authors}

Tijana Vuletic*, Robert lan Whitfield, Wenjuan Wang, Alex Duffy, Scott Gatchell, Henk Prins, Michael Leer-Andersen

*corresponding author

Tijana Vuletic, University of Strathclyde, Design Manufacture and Engineering Management, Level 7, James Weir Building, 75 Montrose Street, G1 1XJ, Glasgow, UK

tijana.vueltic@strath.ac.uk

Robert lan Whitfield, University of Strathclyde, Design Manufacture and Engineering Management, Level 7, James Weir Building, 75 Montrose Street, G1 1XJ, Glasgow, UK

ian.whitfield@strath.ac.uk

Wenjuan Wang, University of Strathclyde, Advanced Forming Research Centre, 85 Inchinnan Dr, Inchinnan, Renfrew PA4 9L

wenjuan.wang@strath.ac.uk

Alex Duffy's affiliation is University of Strathclyde

Scott Gatchell, Hamburg Ship Model Basin, Bramfelder Strasse 164, 22305 Hamburg, Germany gatchell@hsva.de

Henk Prins, Stichting Maritiem Research Institute Nederland, Haagsteeg, PO Box 28, 6700 AA, Wageningen, The Netherlands

h.j.prins@marin.nl

Michael Leer-Andersen, SSPA Sweden AB, Chalmers Tvaergata 10, 40022 Gothenburg, Sweden mla@sspa.se

\section{Abstract}

The first ever model of operational collaboration for the European maritime industry is presented, built upon the established current state-of-the art in engineering collaboration modelling and addressing key industry requirements. The requirements for operational collaboration practices in the European maritime industry were identified using three approaches: an industrial survey of 69 associations, companies and institutions in the maritime sector; an analysis of prototype collaboration tools; and through an analysis of literature. These requirements were thematically grouped and consolidated where they overlapped, and then translated into model elements and interactions between them. A model that accurately abstracts service and technology collaboration provision between companies in a variety of collaboration modes was built, and validated against a 
series of steps that an organisation would need to undertake, to develop a particular mode of collaboration to supports their needs. It was tested in three industrial case studies, providing encouraging feedback demonstrating successful implementation. It provides the opportunity for reassessment of the employed processes and activities, and provides a structure for improving collaborative engineering design. Whilst the research was based in the European maritime industry, the model has wider applicability within the collaborative design of complicated engineering artefacts such as automotive or aerospace.

\section{Keywords}

Operational Collaboration Model, Engineering Design, Maritime Sector, Collaborative Networks, Case Study, Knowledge Management

\section{Introduction}

Collaborative engineering involves a diverse range of themes relating to human factors, technology, organisational characteristics, and trust and intellectual property, which have been investigated individually in numerous industrial and academic contexts. The attempts made to elicit and understand the needs of different collaborative engineering industries, are highly domain specific, limited by the size or type of the group investigated, and tend to focus on a subset of collaborative engineering themes. Typically the focus of past research is either: technical support for collaborative engineering design; system engineering based modelling of a specific design/management process; exploring processes within an organisation; or a relatively closed collaborative operation, aimed at improving collaborative efficiency.

Existing models tend to focus on a specific stage, aspect or type of collaboration.

The supply chain stage has been modelled frequently, and various models exist that explore different aspects of collaboration in the field of supply chain and logistics, e.g. models aiming to assess operational effectiveness of different collaboration tools [1], decisions [2], hierarchies [3], and models aiming to improve information management development [4]. Others focus on a specific aspect of collaboration such as cybersecurity or implementation of specific tools. Bijon, et al. [5] investigated intellectual property issues when groups which are a part of a multilevel system collaborate with outsider consultants on specific projects. Takahashi, et al. [6] developed a cybersecurity operation activity model, and Andert Jr and Morgan [7] explored the implementation of specific tools aimed at collaborative virtual prototyping. Bencic, et al. [8] explored collaboration tools for ship design and production. Zhang and Luttervelt modelled design process information [9]. Models for specific types of collaboration are present as well. Zhang, et al. [10] developed a model of collaboration for e-business. Jiang, et al. [11] developed a context-aware model focusing on international trade. Oppenheim, et al. [12] investigated cross enterprise collaboration within a distributed organisation, Limonad, et al. [13] cross enterprise collaboration for particularly service based organisations, and Hutchins, et al. [14] and Hutchins and Kendall [15] explored team collaboration within an enterprise aimed at problem solving.

Models which focus on inter-organisational collaboration usually have a very specific topic. Chi and Holsapple [16] delivered a model of computer mediate inter-organisational collaboration. Philbin [17] created a process model for university-industry research collaboration. Hocevar, et al. [18] developed a model to enable diagnosis of current collaborative capabilities and guidance in terms of changes required to improve them, and does not focus on technical systems. Xu, et al. [19] developed a model to organise the semantic web services and improve their integration. Anderl, et 
al. [20] described a model of global product development projects which takes into account the changes in organisational structures and operational processes, and puts them in context of the developed products.

Only one model addresses similar issues as the focus of this research. Lau, et al. [21] developed a model and a framework of collaborative development and production, which further develops operational aspects of cross-sectorial inter-organisational collaborative work. However the focus of their model is knowledge-intensive product development, is high level and does not consider specific tools/technologies. While we agree on the necessity of implementation in industrial practice of strategic considerations into operational realm, we approach it in the context of the maritime sector which focuses not only on products, and particularly not only innovative products, but also services, supply chains, simulation and analysis, along with any other activity present in a ship lifecycle. The model presented considers all technical and management activities present in maritime collaborations, inter or cross-organisational, which may include engineering tools and CAD tools, have a range or collaboration types from fully service based to fully technology based, virtual or colocated, and considering a wide range of IP requirements. We explore cross-enterprise crossdisciplinary collaborations, which can take different forms and range from trade to collaborative design and manufacture. They may include CAD/CAM tools, but this is not the only focus. The model provides the flexibility to combine and consider legacy systems and practice/as well as supporting innovation in all aspects of the collaboration.

From a systems engineering perspective, it is necessary to understand and model the interactions between the elements associated with these research themes, in order to reliably improve collaborative efficiency. It is important to understand how collaborative engineering could be modelled and supported from a wider industrial perspective. In creating a collaborative engineering model which spans an industry it is also important to acknowledge that the model should be capable of supporting multiple modes of operational collaboration: different stages of the collaboration process (creating and/or supporting the collaborative network); and different intra/inter organisational boundaries for collaboration.

Creating an operational collaboration model that is accepted by industry, should be the first step towards the development of appropriate collaborative support solutions through the implementation of the model. In constructing a model that is accepted by industry, it is necessary to investigate and capture current industry practice: what industry aims to achieve through collaboration, and what are the stages and the pace at which industry is able to undertake them in order to achieve the aim.

Figure 1 illustrates the requirement elicitation sources, and steps taken towards the operational collaboration model building and evaluation. More detail on requirements elicitation is provided in Section 2, the model in Section 3, and its evaluation in Section 4.

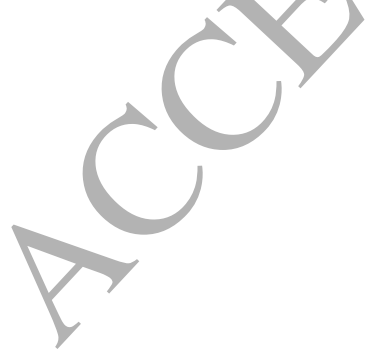




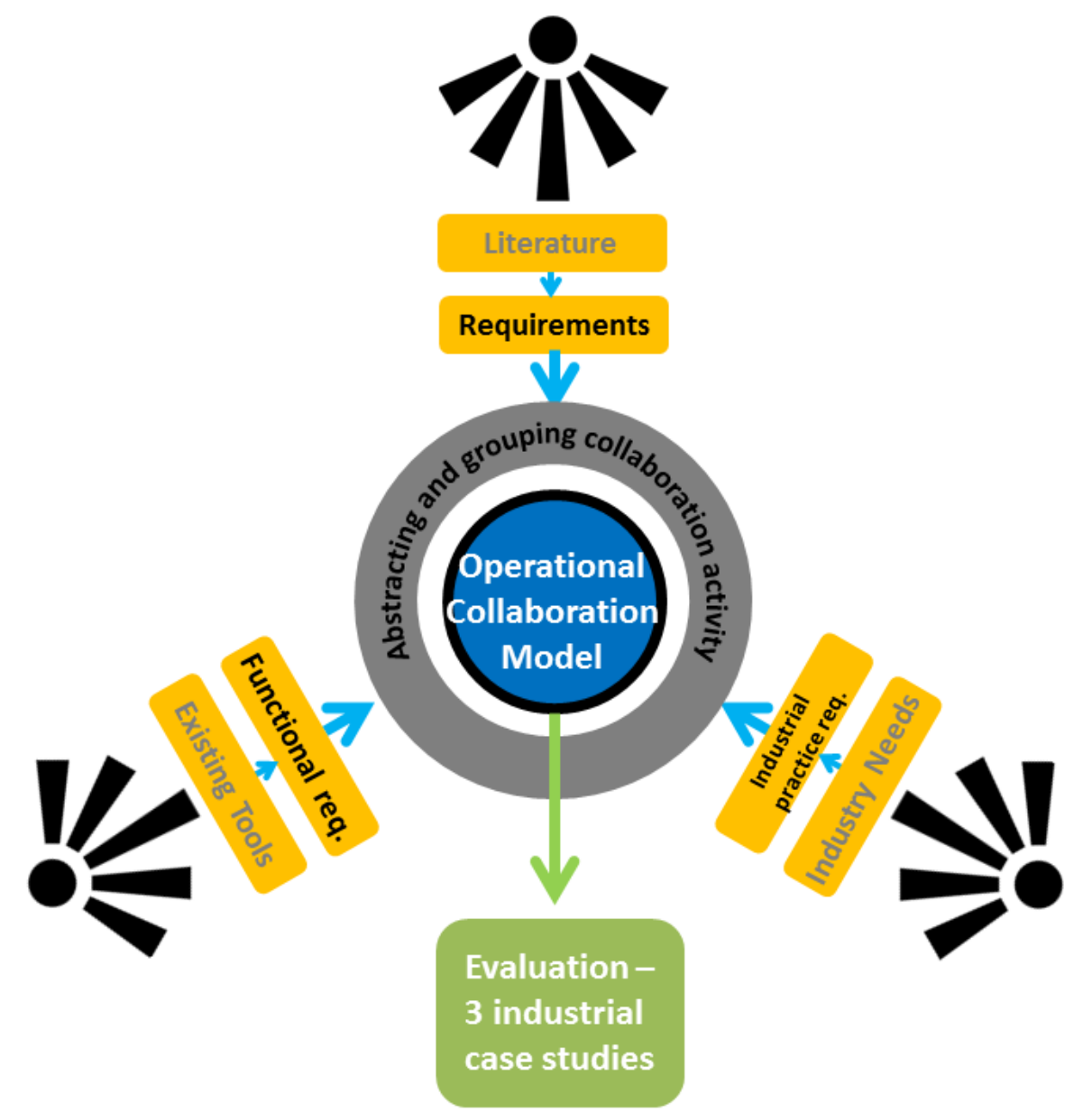

Figure 1 Model building methodology

In this paper we present the first ever operational collaborative engineering model, informed through sector-wide industrial engagement to elicit model requirements, developed by abstracting and grouping collaboration activity, and implemented within two integrated collaborative support systems. The model encapsulates a range of industrial collaboration modes, which were implemented within the maritime industry with the support from collaborative engineering tools, demonstrating its potential to transform current practice. Whilst other models exist within a collaborative engineering context, they are all solution dependent rather than problem dependent. The abstract form of the model allows it to be implemented using alternative collaborative engineering tools, supporting its transferral and application to different industrial sectors. The model was developed within the EuroVIP project, which focused on supporting collaboration between European maritime enterprises. The EuroVIP project consisted of European maritime SMEs, large enterprises, associations and universities who had a common focus of improving collaboration practices through better technology transfer, knowledge exchange, and service provision.

The literature review, presented within Section 2 was undertaken in order to support the initial model development, and then expanded to consider recent developments in the area. The results from the industrial survey and the prototype tools are discussed in the form of requirements for the creation of the operational collaboration model within Section 2. Section 3 describes the model. Case studies demonstrating the model application are described in Section 4 and finally the Discussion and Conclusion are given in Sections 5 and 6. 


\section{Requirements for model development}

Three approaches were used within this research to gather the requirements for the Operational Collaboration Model (OCM) as seen in Figure 1. These three perspectives allowed the creation of a more holistic understanding of what would be required, and formed the foundation for the development of the OCM. The requirements for model development arose from the most significant challenges encountered by researchers exploring collaborative engineering processes generally within an industrial context, industrial practices currently followed in the maritime sector, and practical issues encountered whilst developing prototype collaboration solutions. All requirements are summarised in Table 1.

\subsection{Literature review requirements}

Most collaboration processes involve shared norms and mutually beneficial interactions, through which actors create a structure for the collaboration and create rules to govern their relationships [22]. Actors may work in synergy on attaining the same goal, sharing the risks, resources and rewards; but they may at the same time independently strive to improve their own performance [23-25]. Depending on the needs that different types of organisations may have, their priorities and consequentially the ways in which collaboration takes place can vary [26].

In a collaborative environment, the exchange of information is essential, and is a primary focus of the supporting tools used. To achieve a common and shared understanding amongst participants, they can rely on shared terminology - using a controlled vocabulary to communicate [25]. SMEs tend to collaborate and share knowledge when they have shared domains of interest, but possess different competencies [27, 28]. Knowledge they aggregate over time is often tacit, not always clearly visible and well defined, and will not necessarily be shared [27, 29]. Even if captured, experiential knowledge can become obsolete due to loss of relevance as time passes [23]. Knowledge intensive collaborations often rely on tools that expose patterns of collaboration [30], which can be identified manually or semi-automatically [24]. These patterns can help to group different capabilities together and match companies with related needs, problems or interests [28]. They also contribute to the formalised representation of knowledge, by placing it in context which when added to a database, later facilitates classification, search and acquisition in a structured way $[24,31]$.

Collaboration between previously unaffiliated organisations comes with inherent trust issues, and along with quality, are two of the factors that separates successful from unsuccessful collaborations $[27,32]$. It can influence the foundation of common ground among the collaborators [29]. Using shared terminology often leads to the formation of higher quality collaborative efforts between organisations with vastly different backgrounds and contexts in which they operate, helping to alleviate trust issues [25],

If the collaboration develops over a series of successful engagements, shared experiences of problem solving are accumulated, positively influencing risk acceptance and willingness to commit to closer forms of collaboration. This leads to the preference towards working together to enhance value creation rather than behaving opportunistically in order to attain individual, short-term gain [32]. Communication between the participants and a concept of social presence (the ability of participants to identify with the community), are facilities supporting the trust building [33], as is the post collaboration rating [34]. Once established, trust is not permanent, it fluctuates and depends on the changing relationships of the cooperating partners [35].

The management of complexity is one of the main challenges in solution-dependent engineering based collaborations. Complexity comes from the variety of different organisations in the field, the diversity of relationships between them and the decision making mechanisms employed, and can be dealt with using multiple views and modular architectures [36]. Swarnkar, et al. [37] and Thimm and Boye Rasmussen [38] base their solutions on an IT supported moderator service, enhancing collaboration by improving decision making, supported by a knowledge base and matching users' competencies and capabilities with the collaboration requirements. Whilst both demonstrate 
functionality for certain collaborative engineering support, they also acknowledge the lack of support their solutions provided for context specific, real time collaboration, flexibility, agility and trust building. Stokic, et al. [39] establish the importance of the identification of appropriate expertise and the ability to check the availability of experts and their preferences [40], in order to support the formation of suitable teams. They notice that dynamic changes are the reality of collaborative environments and should be supported appropriately.

Ermilova and Afsarmanesh [41] developed the $4 \mathrm{C}$ competency model while exploring agile and dynamic virtual organisation formation. Afsarmanesh, et al. [42] used the competency database to support virtual organisation formation in a dynamic environment. The 4Cs represent Capabilities (organisational processes and activities), Capacities (free capacities of the organisations' resources needed to perform each capability), Costs (provision of costs of products/services in relation to each capability) and Conspicuities (means for validating the information provided by the members about their capabilities, capacities and costs).

Whilst the teams working on collaborative projects are often geographically distributed, technologies for collaborative communication are almost entirely focused on user to user communication and not on the needs of a collaborative engineering process [31]. Network based platform independent models are considered to be the best solution for inter-disciplinary and geographically distributed collaboration [31, 43]. Tay and Roy [31] developed a prototype for a collaborative CAD/CAM system, focusing solely on design activity. Germani, et al. [43] presented a dynamic collaborative process model for a virtual team, however, its main focus was on the classification of the type of interaction for activities. Neither of the two models address the entire collaboration process or support different stages of the collaboration process or collaboration boundaries.

The literature review has allowed the identification of requirements in a number of areas, which the OCM would need to address. These have been classified by a thematic area (as seen in Table 1), and considered during model development.

\subsection{Industrial practice requirements survey}

European maritime enterprises were surveyed to establish the specific needs relating to current industry collaboration practices and used to elicit operational requirements.

The survey contained 41 questions relating to technology and service collaboration, and information exchanged during collaboration, and was distributed by the EuroVIP partner associations to their members, and by all other EuroVIP partners to their contacts. In addition to exploring current common operational modes of collaboration, the questionnaire also queried how companies prioritised their collaborative activities. Between September and November 2011, 128 replies were collected from associations, companies and research institutions in the maritime sector in Belgium, Denmark, France, Germany, Lithuania, Netherlands, Portugal, Sweden, Turkey, and the UK. Following an initial analysis, 69 of the 128 responses were used for further analysis, since the remaining 59 contained incomplete information. $80 \%$ of the collected replies came from maritime companies with no direct engagement in the EuroVIP project.

The survey results indicated that collaboration has a significant role in the sector, as $71.2 \%$ of the companies stated that they participate in a collaborative business partnership of some sort - Error! Reference source not found. Service-oriented collaboration was more common than technologyoriented, with technology acquisition and provision being roughly equal. The need for a better mechanism for the provision of technology as a service was noticed, as well a better solution for technology transfer. None of the companies were found to produce all of their own components and subsystems. Since it was envisaged that the OCM could be implemented through software solutions, the survey was used to investigate how much software was used within a service context $-38.6 \%$ of the companies surveyed acquired software for design and analysis purposes (either customised from available modules, developed from scratch for their needs, or ready-made and already on offer independently). More detailed findings regarding the top types of service acquisition and provision, and decision factors are given in Figure 3. 
The survey results indicated the use of standard practices for data exchange within the organisation - shared server or file transfer. However, in collaboration with external organisations, particularly if larger amounts of data are exchanged, they were more likely to use email, postal service, physical transfer, and fax, all technologically dated practices.

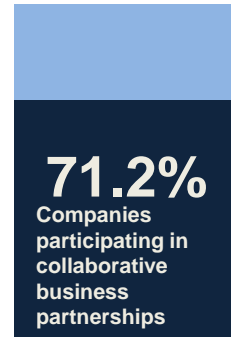

All

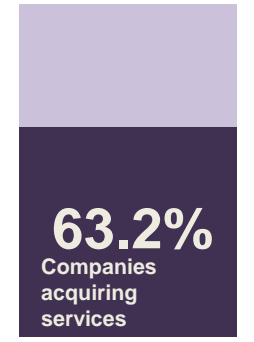

services

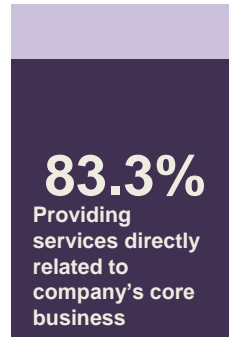

Service

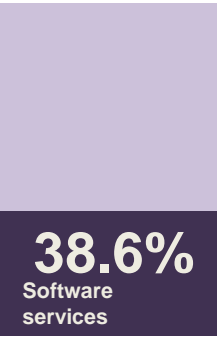

services

Figure 2. Companies engaging in collaboration, split by the collaboration type and direction (providing/acquiring).

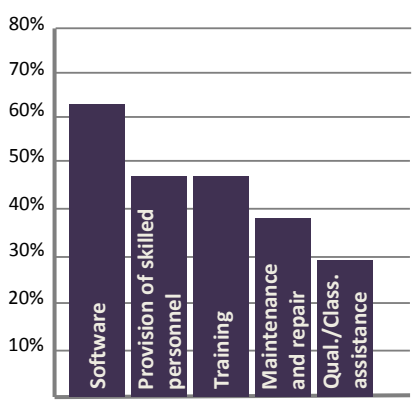

Top service acquisition by type

$$
\begin{aligned}
& \text { Top decision factors for } \\
& \text { service provision/acquisition: } \\
& \text { - Service quality } \\
& \text { - Price } \\
& \text { - Compliance with quality } \\
& \text { standards } \\
& \text { - Timescale of service } \\
& \text { provision }
\end{aligned}
$$

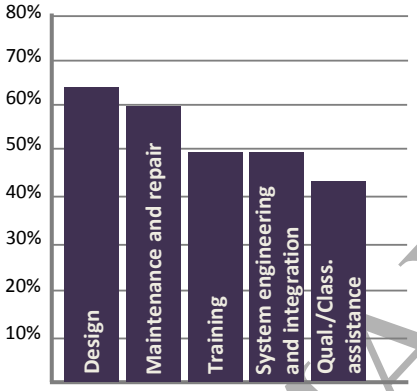

Top service provision by type

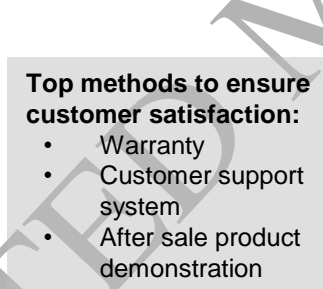

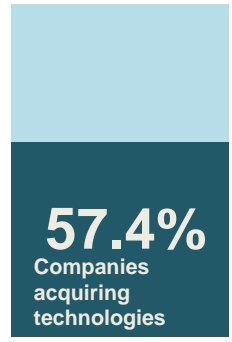

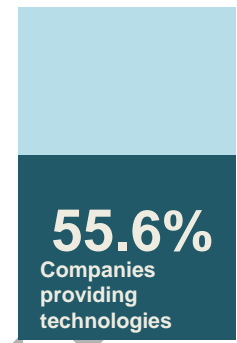

Technology

Figure 3. Specific service/technology acquisition/provision.

$\begin{array}{ll}\text { Types of information } & \text { - } \\ \text { delivered along with } & \text { other } \\ \text { technological equipment: } & \text { products/equipm } \\ \text { - Technical guide } & \text { ent used/legacy } \\ \text { - User guide } & \text { systems }\end{array}$

Compatibility with other systems
Top factors for technology provider selection:

- Equipment quality

- Price

- Timescale of technology provision

- Compliance with quality standards and health and

Internet, personal visits to potential customers, responding to calls for tender and informal contact were identified as the top four methods to promoting business, learning about potential collaborators and identifying a service, technology or information provider. The results indicated that finding a suitable collaborator typically took less than three months.

\subsection{Maritime collaborative systems requirements}

The European maritime industry use collaboration support systems to provide functionality related to sharing processes, resources, and risk. Two systems that were regarded as being reflective of the types of collaborative functionality available, were used in order to facilitate the requirements elicitation. These systems were analysed in order to establish the associated functional requirements that the OCM should support.

EuroVIP project partners were familiar with the VIP (Virtual Integration Platform), system used to support collaboration processes in engineering design and optimisation. The VIP allowed geographically distributed designers and analysts to collaborate within the context of a design process through sharing product and process related information. Engineering design and analysis tools could be integrated and operated in a unified and holistic manner allowing distributed engineers working on different tasks, using different tools, to collaborate and share their design and 
management understanding within the same design process [44]. The VIP had evolved through research within a number of European integrated design projects that had focussed on supporting collaboration for through-life design; computational fluid dynamics; and safety, all within the maritime industry.

Within the early stages of OCM development, a prototype version of the European Maritime Collaboration Portal (EMCP) was created to further support requirements elicitation. The EMCP philosophy was to provide service oriented collaborative support, based on the consortium's extensive experience in the maritime sector and the commonly established knowledge of the European maritime sector needs. The prototype EMCP provided the foundation for this functionality, and was constantly developed throughout the project. Both the VIP and EMCP facilitated the elicitation of functional requirements for the OCM from the industrial partners and the wider maritime community throughout the duration of the EuroVIP project collected though project meetings; feedback from project partners; and using periodic surveys.

These systems were developed by the authors of this paper. A version of VIP existed prior to the requirements identification process as an output of earlier research within this industry [44]. The EMCP was developed during the EuroVIP project, concurrently with the OCM, and prototyped on the requirements collected from the survey and the literature. Requirements and solution co-evolution took place, following a SCRUM methodology, and both VIP and EMCP were critiqued by industry with regards to the types of collaboration needed in order to better understand the requirements of the OCM. New requirements were identified and addressed throughout the project using this methodology and were used in the model development. Only these new requirements are reported in this paper. The SCRUM methodology originates as a software development methodology, employing an iterative and incremental development approach. It provides a framework to dynamically reflect ad hoc situations and support close collaboration between the requirement influx and the project team. This strategy incorporated iterations of discovery, realisation, and impact that last throughout the project by elucidating the challenges and requirements, realising mechanisms to address the requirements, and analysing the impact.

\subsection{OCM requirements summary}

The requirements generated from the industrial survey, collaborative support systems and literature review were grouped into key thematic areas that were considered to be necessary for the OCM to support: knowledge management, trust; data and information; collaboration; and technical. These key requirements are summarised in Table 1 , indicating the area, requirement and source.

Table 1. OCM requirements (LR- Literature review, IPS - Industrial Practice Survey, FR - Functional Requirements)

\begin{tabular}{|c|c|c|c|}
\hline Thematic Area & Requirement & Source & Req.no. \\
\hline $\begin{array}{l}\text { Knowledge } \\
\text { management }\end{array}$ & $\begin{array}{l}\text { Provide a structure/format for the information knowledge base } \\
\text { [22] }\end{array}$ & LR & LR1 \\
\hline $\begin{array}{l}\text { Knowledge } \\
\text { management }\end{array}$ & $\begin{array}{l}\text { Provide the context for the knowledge (to enable classification, } \\
\text { search, acquisition) [24] }\end{array}$ & LR & LR2 \\
\hline $\begin{array}{l}\text { Knowledge } \\
\text { management }\end{array}$ & Use shared terminology [25] & LR & LR3 \\
\hline $\begin{array}{l}\text { Knowledge } \\
\text { management }\end{array}$ & $\begin{array}{l}\text { Record information about best practices, communication etc. } \\
\text { [31] }\end{array}$ & LR & LR4 \\
\hline $\begin{array}{l}\text { Knowledge } \\
\text { management }\end{array}$ & Expose collaboration patterns [30] & LR & LR5 \\
\hline $\begin{array}{l}\text { Knowledge } \\
\text { management }\end{array}$ & Better search capabilities & IPS & IPS1 \\
\hline $\begin{array}{l}\text { Knowledge } \\
\text { management }\end{array}$ & Basic and "clever" search & $\mathrm{FR}$ & FR1 \\
\hline $\begin{array}{l}\text { Knowledge } \\
\text { management }\end{array}$ & $\begin{array}{l}\text { History (record events, messages, meetings, ability to look back } \\
\text { and see why decisions were made) }\end{array}$ & $\mathrm{FR}$ & FR2 \\
\hline Knowledge & Classification of information into domains, categories, groups and & FR & FR3 \\
\hline
\end{tabular}




\begin{tabular}{|c|c|c|c|}
\hline Thematic Area & Requirement & Source & Req.no. \\
\hline management & sub-groups & & \\
\hline $\begin{array}{l}\text { Knowledge } \\
\text { management }\end{array}$ & $\begin{array}{l}\text { Up to date information about service/technology providers } \\
\text { (including information about cost) }\end{array}$ & $\mathrm{FR}$ & FR4 \\
\hline Trust & $\begin{array}{l}\text { Alleviate trust issues (e.g. communication, social presence, sense } \\
\text { of community, risk assessment, ratings, recalling successful } \\
\text { collaboration patterns) }[25,33-35]\end{array}$ & LR & LR6 \\
\hline Trust & Tools to control data privacy levels & $\mathrm{FR}$ & FR5 \\
\hline Data and Information & $\begin{array}{l}\text { Deal with complexity (data exchange, requirements, flexible and } \\
\text { dynamic collaborations etc.) [36-38] }\end{array}$ & LR & LR7 \\
\hline Data and information & $\begin{array}{l}\text { Display appropriate and up to date capabilities, capacities, costs, } \\
\text { conspicuities }[41,42]\end{array}$ & LR & LR8 \\
\hline Data and Information & Reliable information on technology/service & & IPS2 \\
\hline Data and information & $\begin{array}{l}\text { Detailed descriptions of capabilities for technologies (includ } \\
\text { price, timescale, information on aftersales support, quality etc. }\end{array}$ & & IPS3 \\
\hline Data and information & News and latest updates & & FR6 \\
\hline Collaboration & Support team formation $[37,38,40]$ & LR & LR9 \\
\hline Collaboration & $\begin{array}{l}\text { Support different types of organisations and different priorities } \\
\text { [26] }\end{array}$ & LR & LR10 \\
\hline Collaboration & $\begin{array}{l}\text { Clearly defined structure to support the collaboration formation } \\
\text { and collaboration processes }\end{array}$ & IPS & IPS4 \\
\hline Collaboration & Mechanism for the provision of technology as a service & IPS & IPS5 \\
\hline Collaboration & Support for technology transfer & IPS & IPS6 \\
\hline Collaboration & Communication facilities & FR & FR7 \\
\hline Technical & Network based and platform independent [31] & LR & LR11 \\
\hline Technical & Secure methods for data and information exchange & IPS & IPS7 \\
\hline Technical & $\begin{array}{l}\text { Support features (for both different languages and different } \\
\text { devices) }\end{array}$ & $\mathrm{FR}$ & FR8 \\
\hline Technical & Billing system & FR & FR9 \\
\hline Technical & Link between the service and technical tools & FR & FR10 \\
\hline Technical & $\begin{array}{l}\text { Facilities enabling smooth cooperation and data transfer } \\
\text { between collaborators }\end{array}$ & $\mathrm{FR}$ & FR11 \\
\hline
\end{tabular}

\section{Operational Collaboration Model}

The requirements elicited within Section 2 were thematically grouped into areas, and consolidated where overlaps existed, providing the basis for the OCM development. This consolidated requirements set was used to determine the types of elements that could exist within the OCM, and the nature of the interactions between them. For example, the knowledge management requirement to "use shared terminology" was translated into elements within the OCM that would support the delivery of the requirement: a template describing service or technology provision; a dictionary that suggested commonly used terminology to facilitate completing the template; a facility to allow the creation of new terminology; keyword search; tagging of terminology; and categorising information within the repository.

The interactions between the elements of the OCM took the form of information exchange, with the OCM subsequently taking the form of a process model. The OCM would be required to support the differing nature of engagement a company would have within a collaborative partnership company: the company may place importance on being able to control and manage the collaboration process; it may require equal decision-making powers as the collaborator, or may require flexibility on project management and control for each new project. These considerations would lead to different modes of organisational collaboration support provision. Similarly, the content and type of the collaborative project would require different organisational modes of support.

Cagliano et al. defined nine collaboration modes that both guide and limit collaborative partnerships as: networking, minority equity, join venture, formal agreement, informal agreement, consortium, 
licensing, (sub) contracting, and outsourcing [26]. They defined the frequency of interaction between the collaborators and their needs range from those requiring high levels of confidentiality, to those that might prefer widespread publicity; from purely service based collaborations to very integrated collaborative processes requiring different types of data exchanged between different organisations.

Figure 4 shows a high level version of the OCM, showing the three key blocks of the model, structure of the aspects of the model within them, and their interactions. The OCM is a process model, and the more detailed process elements and their interconnections can be seen in Figure 5, Figure 7 and Figure 8 for each of the three blocks of the OCM. While OCM reflects a process, there is no single defined path through it that collaboration should take, and depending on the specificities of each collaboration the elements of the model employed are different. Examples of four typical collaboration processes, defined as levels of collaboration, will be given in Section 3.3 and examples of specific collaborative activities tested during the case studies will be given in Section 4 .

Collaborative activities can start with a call for collaboration (falling under content generation box) specifying the collaborative activities, or editing information already existing in the repository (content interaction box). The repository is used to retrieve and record information throughout the collaborative process (repository box). The Knowledge Base block provides support for collaboration, collation of information and in certain collaborations is a starting point. The Requirements \& Options block and Collaboration block are typically more sequential. Collaborations are further defined (collaboration orchestration box), teams formed, expertise available, resources and capacities established (collaboration coordination box), and collaboration set up and initialised (collaboration initialisation box) in the Requirements \& Options block. The collaboration process progresses to the Collaboration block where the collaboration facilitation happens, service collaboration facilitation (facilitating communication box), technical collaboration facilitation (technical collaboration box), training technology transfer (technology transfer box), collaboration evaluation (evaluation box), and customer support, after sale, warranty and additional services offered (post collaboration support box). Each box is annotated in the bottom right corner, with EMCP, VIP or both. This annotation denotes how the model is facilitated during the implementation, and more information on this is given in Section 3.3. Only one element of the model could be implemented using either VIP of EMCP, and that is collaboration initialisation. Which implementation system would be used is dependent on many parameters some of which are which enterprises are involved in collaboration, what tools they are using, the type of the collaboration, and the type of information exchanged. 


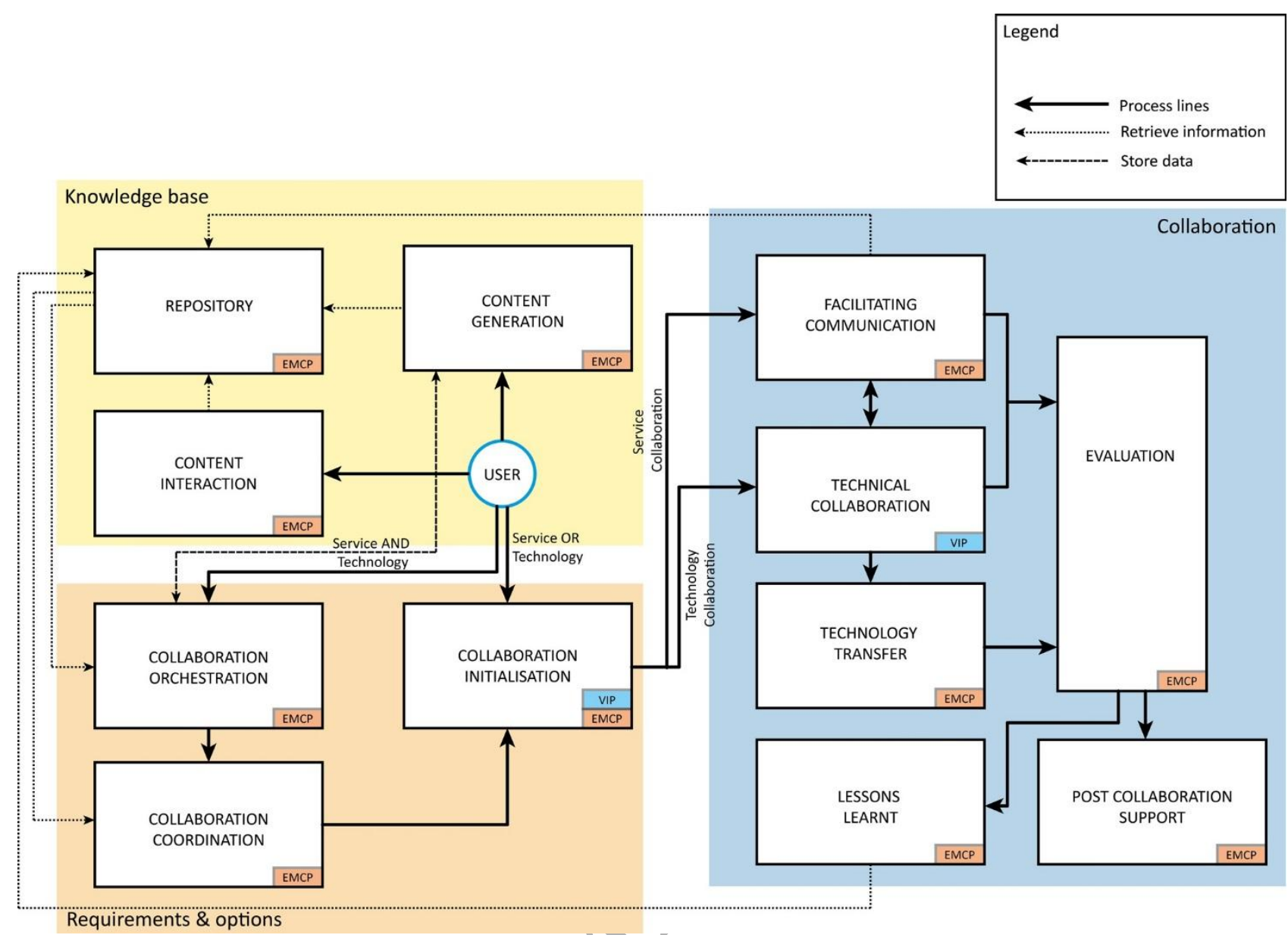

Figure 4. Operational Collaboration Model (OCM)- high level.

The OCM was validated by industry, for each collaboration mode, by checking that appropriate support was modelled for the steps that industry would need to undertake. For example, the OCM was tested against a scenario for a company interested in forming a technology focussed collaborative partnership, where the partnering companies were not defined. This particular scenario would mean that the company does not have a process defined a priori, has to search for collaborators based on the project requirements, negotiate the terms of collaboration, set up the collaboration parameters, define goals, form the teams, plan their activities, perform the technology collaboration and finally produce the required output. If the support for any of these steps was not modelled within the OCM, or if some step or activity was not available the OCM was adapted accordingly. If necessary, literature was consulted again and/or requirements were revisited. When finalised, the OCM was released to the project partners for feedback. Two rounds of revision were performed, based on the partners' feedback.

\subsection{Model description}

The OCM abstracts the service and technology collaboration between companies in a variety of different collaboration modes. Due to the physical size of the OCM it is presented through its three main components - Knowledge base in Section 3.1.1, Requirements \& Options in Section 3.1.2 and Collaboration in Section 3.1.3. The Knowledge base component focuses on the repository designed to facilitate storage and retrieval of collaboration process information. The Requirements \& Options component describes the necessary steps to construct a collaborative network, by finding the best trade-off between the project requirements and collaborators' competencies and availability. The Collaboration component focuses on the operational collaboration steps performed after the collaborative teams are formed. At this stage within the OCM, the collaborative network is well 
defined and the Collaboration component provides structure and organisation of the supporting technology and service.

Observing the activities performed throughout the entire OCM for the creation of a collaborative network the three components of the OCM are used sequentially. The Knowledge base component provides an information source and knowledge support facility, while the Requirements \& Options and Collaboration components form a chain of sequential activities and decision points which are to be completed in order to create and then operate a collaborative network. However, when considering the data and information flows, the Requirements \& Options and Collaboration components are connected to the Knowledge base component at various points, either providing it with newly collected data or retrieving already existing data from it.

Figure 5, Figure 7 and Figure 8 provide a more detailed illustration of the processes within each of the blocks and boxes of the model given Figure 4 . To be concise the paper focusses on the key points relating to the model structure and will not provide detail of all of the elements shown in the figures where it is considered to be self-explanatory.

\subsubsection{Knowledge base}

The Knowledge base describes the structure of the mechanisms used for data generation, storage and retrieval and is illustrated in Error! Reference source not found.

The main feature of the Knowledge base is the data repository (Figure 4, Figure 5) which contains information to support collaboration relating to:

- categories based on keywords/tags assigned to the service, technology, information and company content;

- meta-information on Capabilities, Capacities, Costs and Conspicuities that the different entries within the data repository possess; and,

- knowledge of collaboration ratings, problem areas, patterns of collaborative behaviour, and best practices identified in the completed collaboration processes in order to facilitate the development of trust.

The starting point for a new user is population of the Knowledge base through content generation (Figure 4, Figure 5) and the provision of company specific information, for example name, location, domain, and expertise that is structured to match with the repository data architecture. The data is assigned an appropriate permission (custom - visible to selected users only; or public - visible to all users), where the permission levels control the content's visibility and are used to determine who receives notifications of new content. Keywords are used to organise the data in different categories, to ensure better usability with respect to searching for information and managing future collaboration opportunities.

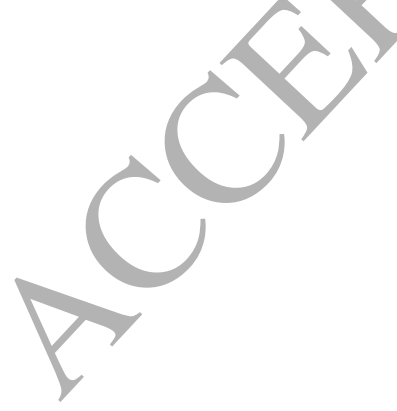




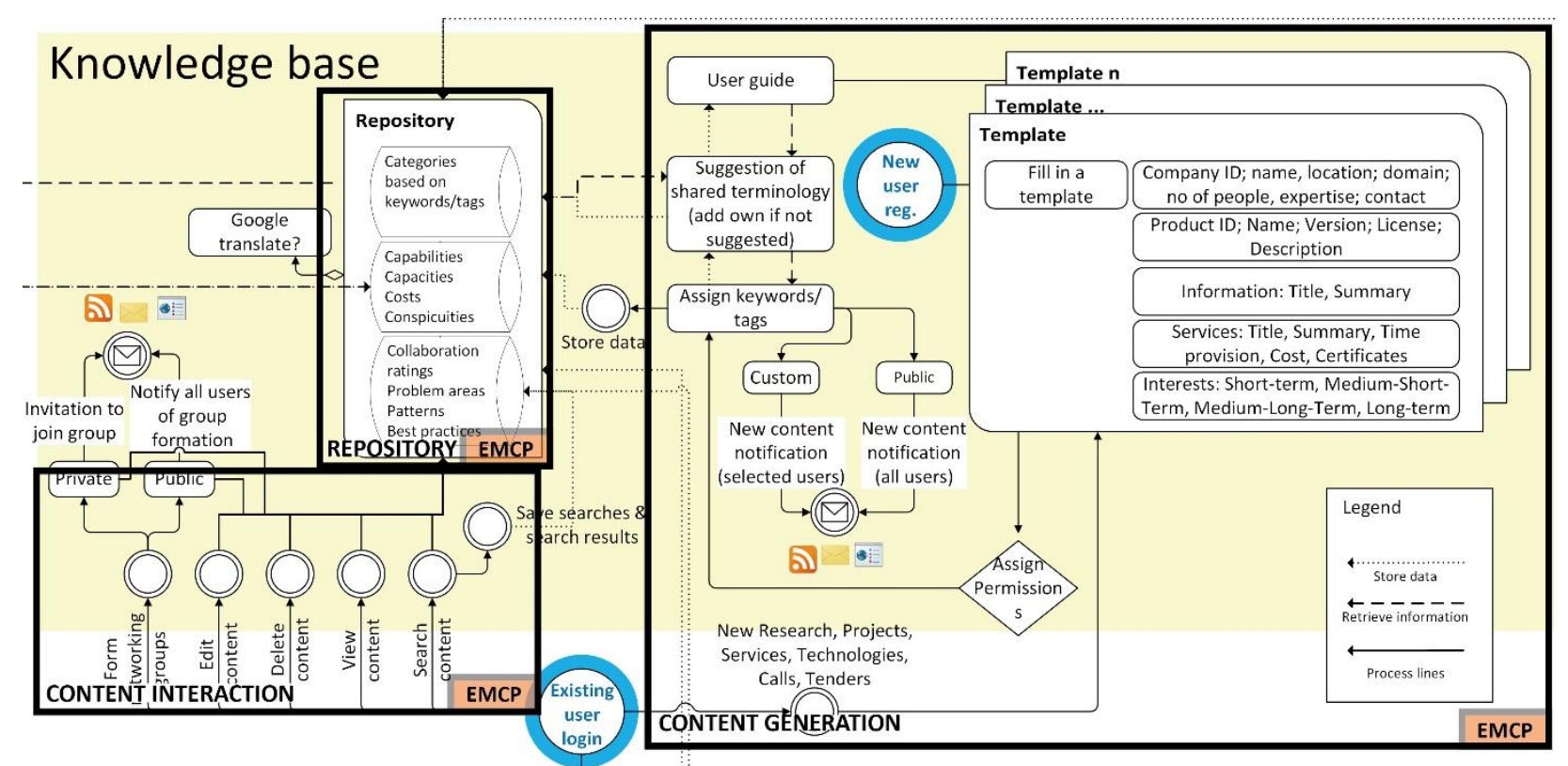

Figure 5. Operational Collaboration Model - Knowledge base component.

Challenges exist with respect to the use of different terminology, further compounded by the wide range of languages used within European maritime community. The OCM acknowledges this by proposing that support should be provided to ensure established terminology suggestions in the form of vocabulary suggestions or guidance. This shared terminology element of the OCM would learn on the basis of the keywords that users provide, building up a list of suggested terms. The Knowledge base element of the OCM provides functionality to allow users to view public entries, search the content of the repository, and edit and delete their own content as necessary (content interaction, Figure 4, Figure 5). A record of searches will be added to the repository and used to identify patterns of collaboration. Users can form groups which enable them to discuss and exchange data regarding specific projects or themes. Public groups are open to all users, whilst private groups can only be joined through invitation.

\subsubsection{Requirements \& Options}

The industrial survey response indicated that collaboration is oriented towards a combination of service and technology provision. When a company initiates a collaborative partnership, the Requirements \& Options component distinguishes between either service or technology, or some combination thereof. This distinction governs the sequence of activities that will gather specific requirements relating to supporting the development of the collaborative partnership.

A top down collaboration mode is adopted when no defined workflow exists that is mapped to the capability and experience of the companies registered within the Knowledge Base, a top-down collaboration mode will be adopted and a search for missing capabilities will be performed. This mode is initiated with a Knowledge Base search for the missing capability using requirement, constraint and deadline criteria. If the user wishes to define the points and frequency of interactions they also need to specify the collaboration priority mode, in order to select the detailed options relating to data exchange, and interaction points for example.

The top-down collaboration mode has two major applications:

1. The configuration of a new collaborative partnership from scratch, requiring the definition of the collaborative design project as well as the collaborators.

2. The integration of external service or technology providers in order to complete the configuration of the capability for a new collaborative project.

Either of these applications requires a company to search for a desired resource using information contained within the repository (collaboration orchestration, Figure 4 and Figure 7). 
If the collaboration is a combination of service and technology, and the Knowledge Base repository contains details of potential providers that match the requirements, the approach to supporting the collaboration will be bottom up using information within the Knowledge Base that satisfies the requirements. This would be the case if a previous collaboration workflow and associated collaborators contained within the workflow could be reused; or if the company aiming to collaborate has defined a new workflow that is mapped to the capability and experience of companies registered within the Knowledge Base. The request for a specific service or technology would be made to replace an existing, or attain a new capacity, and following the acquisition of the service/technology the collaboration (through collaboration orchestration, Figure 4 and Figure 7) would progress to the Collaboration component. Any legal implications such as agreements or contracts would be handled between the collaborators, independent of the OCM.

The bottom up mode of collaboration reflects a scenario where a company would have an established collaborative design project. The OCM supports searching for appropriate resources in the repository either due to lack of capability to perform an activity, or due to the change in the needs for the collaboration. The top down and bottom up collaboration modes are illustrated in Figure 6.

The detailed options for the collaboration priority mode are defined once the collaboration call is published. Three possible starting points for defining these options are: organisation mode priority when collaboration is defined largely by the constraints of the company and the rules it is governed by, such as legal and intellectual property considerations; control mode priority - when collaboration is influenced primarily by decision making authority; and, content mode priority when collaboration is governed primarily by the expected goal and nature of the work content. A company could decide to prioritise only one collaboration organisation mode, or adopt any combination of them. For example, a defence company would primarily be concerned with security and data confidentiality, therefore control mode, would have the priority and guide the collaboration choices.

A consortium where each member organisation, with different working cultures and experiences, contributes towards the final product design would value the importance of sequencing the activities in a more efficient way, therefore organisational mode would govern the collaboration choices. Finally, a company working on an R\&D project where having a functional final output of the work performed is the most important aspect, would likely value the content mode the most, as all decisions they make would be guided by the nature of the product being developed.

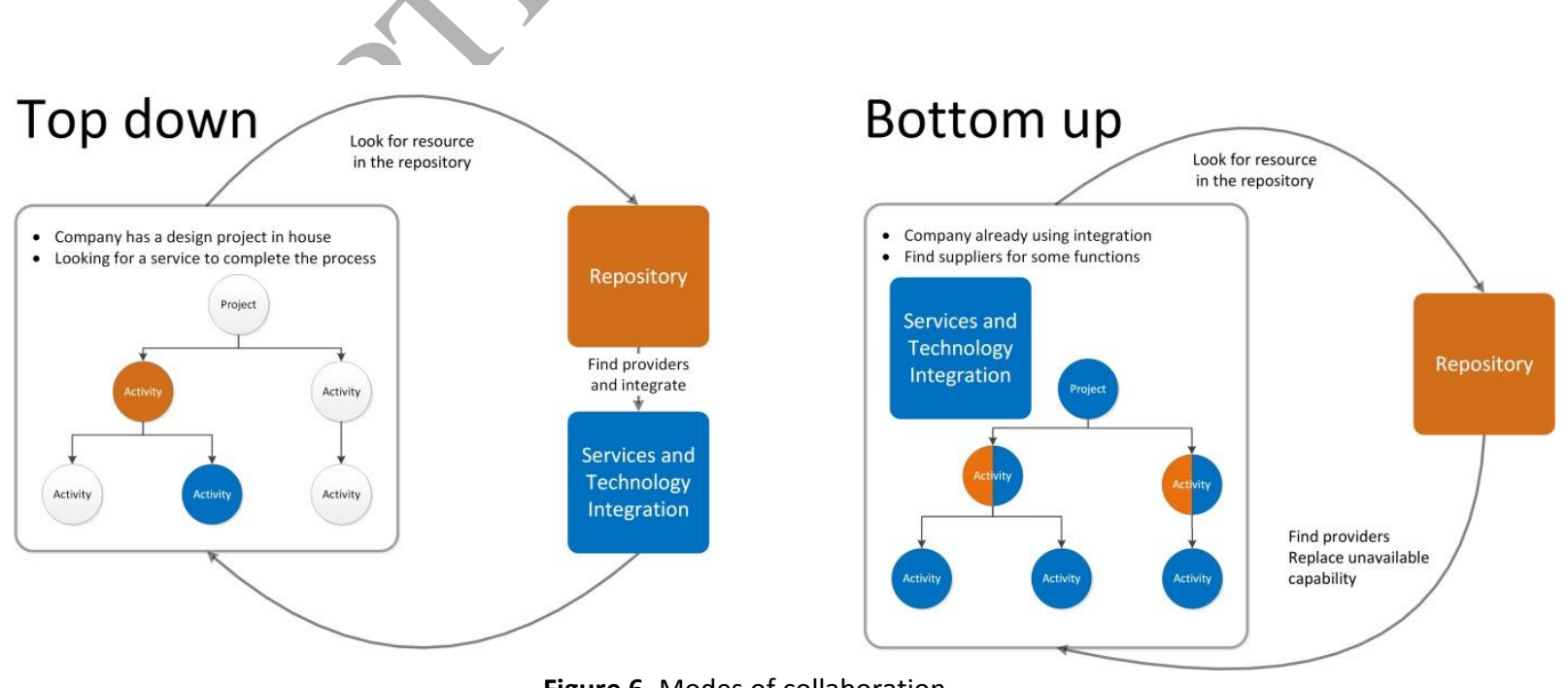

Figure 6. Modes of collaboration.

Once the collaboration priority mode and options have been defined, and tenders to the published call have been received, the company that published the call will have to assess how the 
technologies or services offered in response to the call satisfy their requirements. The most important service/technology factors as described in Section 2, such as equipment quality, price, timescale of technology/service provision are illustrated in Figure 3. When a suitable service/technology is identified, the potential collaboration can be negotiated using the standard practices that the companies follow. This entire process is represented in the collaboration orchestration box in Figure 7 and it can be repeated as many times is necessary to complete the collaboration requirements definition process.

Once collaboration orchestration has been completed, the goals of the collaboration need to be defined and the availability of experts, capacity and resources need to be managed. This information can be retrieved from the repository, and needs to be accurately recorded once a capacity is assigned to a project to reflect the changes in availability. The plan of activities is then consolidated (through collaboration coordination, Figure 4 and Figure 7) and the collaboration progresses to the Collaboration component, as illustrated in Figure 7.

If companies already know who they want to collaborate with, have a clearly defined workflow for a service or technology collaboration, and do not want any assistance to set up the collaboration, they can choose to move directly to the Collaboration component, and this path is shown in the collaboration initialisation box (Figure 4 and Figure 7).

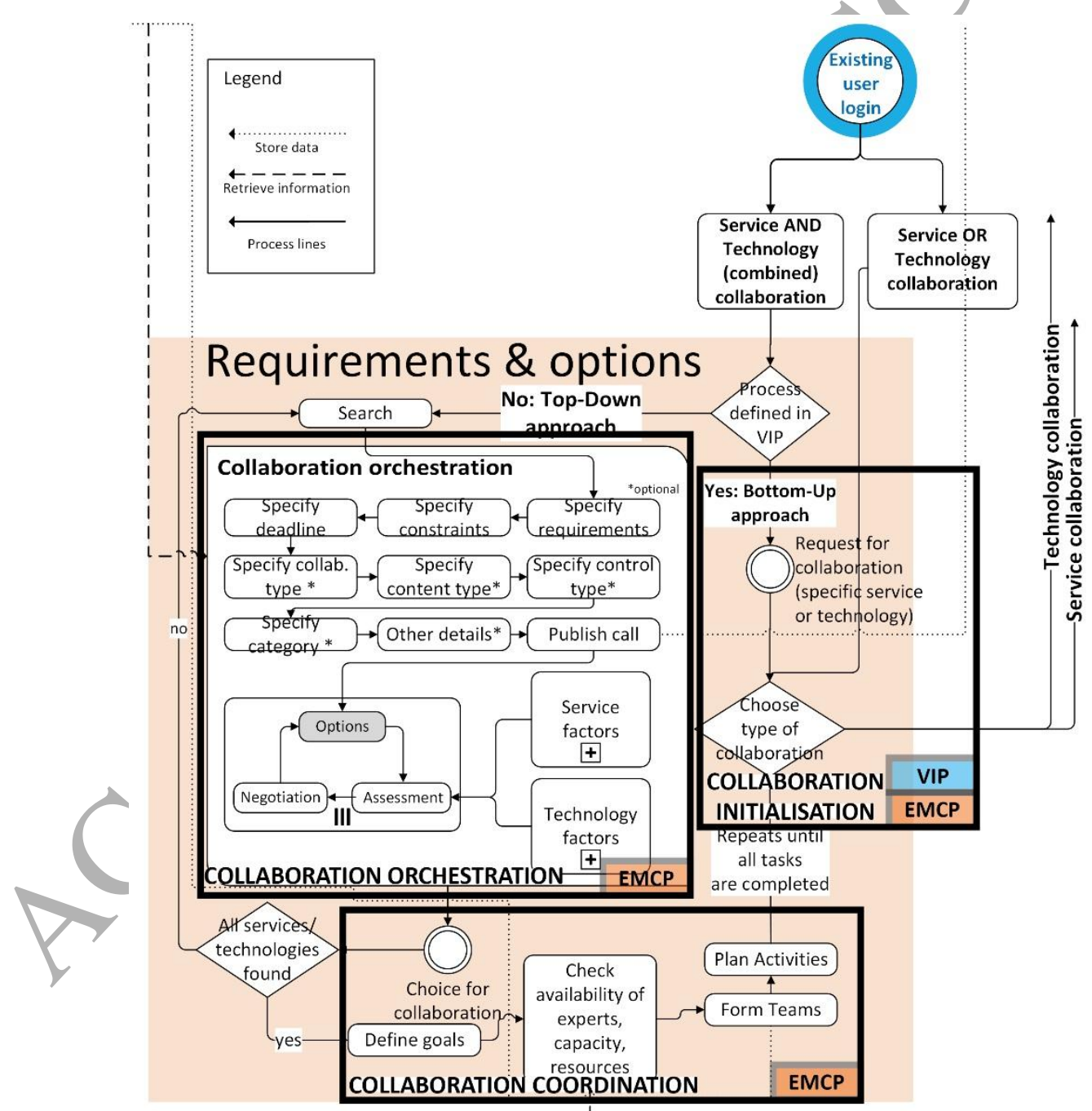

Figure 7. Operational Collaboration Model - Requirements \& Options component.

\subsubsection{Collaboration}

Service, technology and combined collaboration types will have different requirements, but the layout of the Collaboration component illustrates the process for satisfying the requirements for 
these different types. The process starts by supplying the currently available data as either service or technology inputs as illustrated in Figure 8.

The OCM indicates the communication-oriented support for undertaking service-based collaborations are related to providing appropriate functionality to managing task and data ownership, data exchange and information storage (facilitating communication box, Figure 4 and Figure 8). Following project completion, the results are evaluated, and the results and their evaluation form the output of the project (evaluation box, Figure 4 and Figure 8).

A technology-based collaboration will firstly be required to identify the process to follow and the tools to be used. These tools would need to be integrated in the collaboration process, and used to perform the associated design and analysis tasks, and finally some type of visualisation of results would follow (technical collaboration box, Figure 4 and Figure 8). The results would then be evaluated and would at that point represent the output of the technology collaboration (evaluation box, Figure 4 and Figure 8). In addition to the exported technical data the outputs can take a form of warranties, customer support systems, after sale product demonstrations or be followed by an offer of additional services - maintenance and repair plans, continued consultancy, design, system engineering, and training (post collaboration support box, Figure 4 and Figure 8). Technology can also be provided as a service; for example if one company provides an analysis that another company does not have capacity for, but requires to complete their process. In this case, some form of technology transfer might be necessary before evaluation of the results, and the details of this transfer agreed between the companies prior to the start of the collaboration (technology transfer box, Figure 4 and Figure 8).

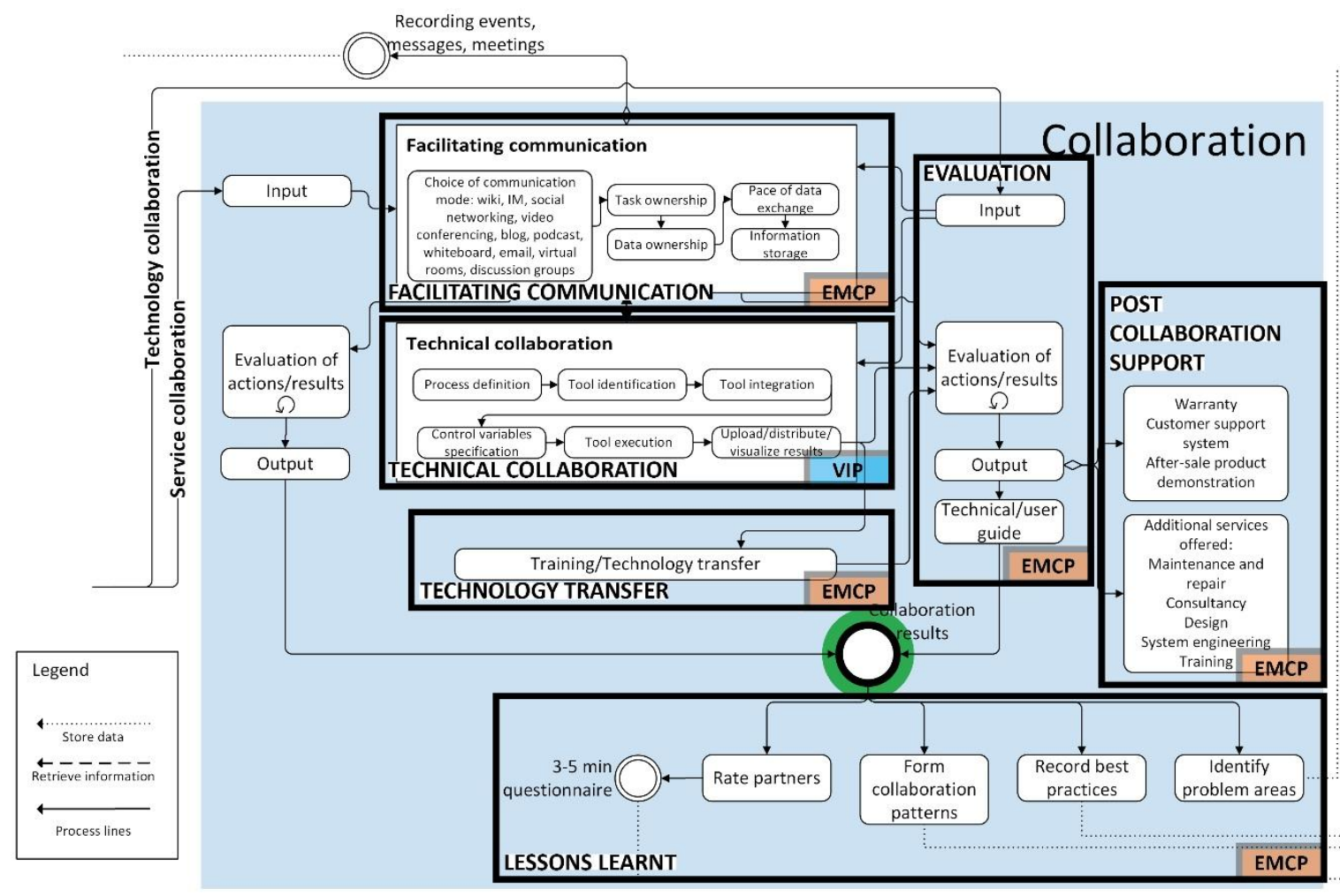

Figure 8. Operational Collaboration Model - "Collaboration" component.

Collaboration may start as service-oriented and then transform into technology-oriented with occasional usage of the service facilities to obtain necessary information mid-way, finalising as technology collaboration. When implemented, each collaboration process would be unique and tailored to the needs of the companies and the nature of the project.

Following the project completion, the companies would rate the partners using a short questionnaire with this information added to the repository for future use, improving the 
information reliability and helping inform trust decisions. Additionally, the repository stores the collaboration patterns, best practices and problem areas identified during the project for future use (lessons learnt box, Figure 4 and Figure 8).

\subsection{Implementation of requirements in different blocks of the model}

As discussed in Section 2, the requirements provided in Table 1 were used as a basis for the OCM development. Figure 9 shows the matrix linking the identified requirements to different features of the OCM built to address those requirements, and the facility used to implement the model for each section (VIP or EMCP).

\begin{tabular}{|c|c|c|c|c|c|c|c|c|c|c|c|c|c|}
\hline & & & wledge & & Requi & ements \& C & otions & & & Collat & ation & & \\
\hline & & 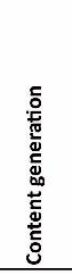 & 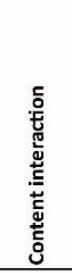 & 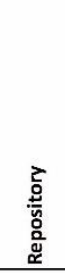 & 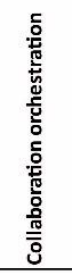 & 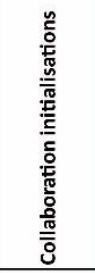 & 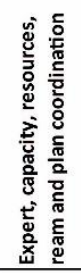 & 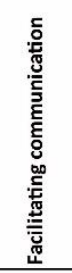 & 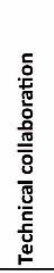 & 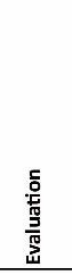 & 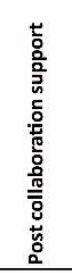 & 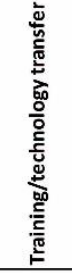 & 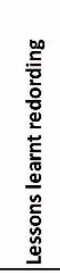 \\
\hline Req. No & Thematic area & EMCP & EMCP & EMCP & EMCP & $\begin{array}{c}\text { EMCP or } \\
\text { VIP }\end{array}$ & ЕMCP & EMCP & VIP & ЕМСР & EMCP & EMCP & EMCP \\
\hline FR1 & Knowledge management & & & & & & & & & & & & \\
\hline FR2 & Knowledge management & & & & & & & & & & & & \\
\hline FR3 & Knowledge management & & & & & & & & & & & & \\
\hline FR4 & Knowledge management & & & & & & & & & & & & \\
\hline FR5 & Trust & & & & & & & & & & & & \\
\hline FR6 & Data and information & & & & & & & & & & & & \\
\hline FR7 & Collaboration & & & & & & & & & & & & \\
\hline FR8 & Technical & & & & & & & & & & & & \\
\hline FR9 & Technical & & & & & & & & & & & & \\
\hline FR10 & Technical & & & & & & & & & & & & \\
\hline FR11 & Technical & & & & & & & & & & & & \\
\hline IPS1 & Knowledge management & & & & & & & & & & & & \\
\hline IPS2 & Data and Information & & & & & & & & & & & & \\
\hline IPS3 & Data and information & & & & & & & & & & & & \\
\hline IPS4 & Collaboration & & & & & & & & & & & & \\
\hline IPS5 & Collaboration & & & & & & & & & & & & \\
\hline IPS6 & Collaboration & & & & & & & & & & & & \\
\hline IPS7 & Technical & & & & & & & & & & & & \\
\hline LR1 & Knowledge management & & & & & & & & & & & & \\
\hline LR2 & Knowledge management & & & & & & & & & & & & \\
\hline LR3 & Knowledge management & & & & & & & & & & & & \\
\hline LR4 & Knowledge management & & & & & & & & & & & & \\
\hline LR5 & Knowledge management & & & & & & & & & & & & \\
\hline LR6 & Trust & & & & & & & & & & & & \\
\hline LR7 & Data and Information & & & & & & & & & & & & \\
\hline LR8 & Data and information & & & & & & & & & & & & \\
\hline LR9 & Collaboration & & & & & & & & & & & & \\
\hline LR10 & Collaboration & & & & & & & & & & & & \\
\hline LR11 & Technical & & & & & & & & & & & & \\
\hline
\end{tabular}

Figure 9. Relationship between the requirements and OCM sections.

Darker fields indicate the facilitation has been fully addressed for a basic case. Lighter fields indicate that some capability exists, but to reach full capability further work is required.

\subsection{Tailoring of collaboration}

Successful collaborative partnerships are required to be tailored to the needs of the organisations involved, which could potentially lead to a wide range of different ways to collaborate; four main levels of collaboration are identified, and are defined by the following parameters:

- Nature of interaction between the companies

- Nature of technical support necessary

- Confidentiality requirements

- Quantity and the type of the information exchanged 
The four levels of collaboration have been created to allow flexibility: collaboration may correspond to one of the four levels, between levels, or different stages of collaboration may span the levels. Figure 10 illustrates how the VIP and EMCP are expected to be used in the four typical levels of collaboration. Figure 11 shows which elements of the model would certainly be used in each of the four levels (levels of collaboration are denoted with a number in a circle to the left of the each box). Some elements of the model do not have a circle next to them, illustrating that they are not the part of the key path through the model. The extent of their use would depend on a specific collaboration. Service-based collaboration (Figure 10, Figure 11 denoted with number 1 ) depicts collaboration that primarily uses the repository for search, data exchange and the negotiation process. It may utilise different design and analysis tools, so that a company could either provide or acquire technology as a service. There would be no design and analysis tools integrated within the collaboration process and the company acquiring the technology would not need to have access to them or be trained to use them.

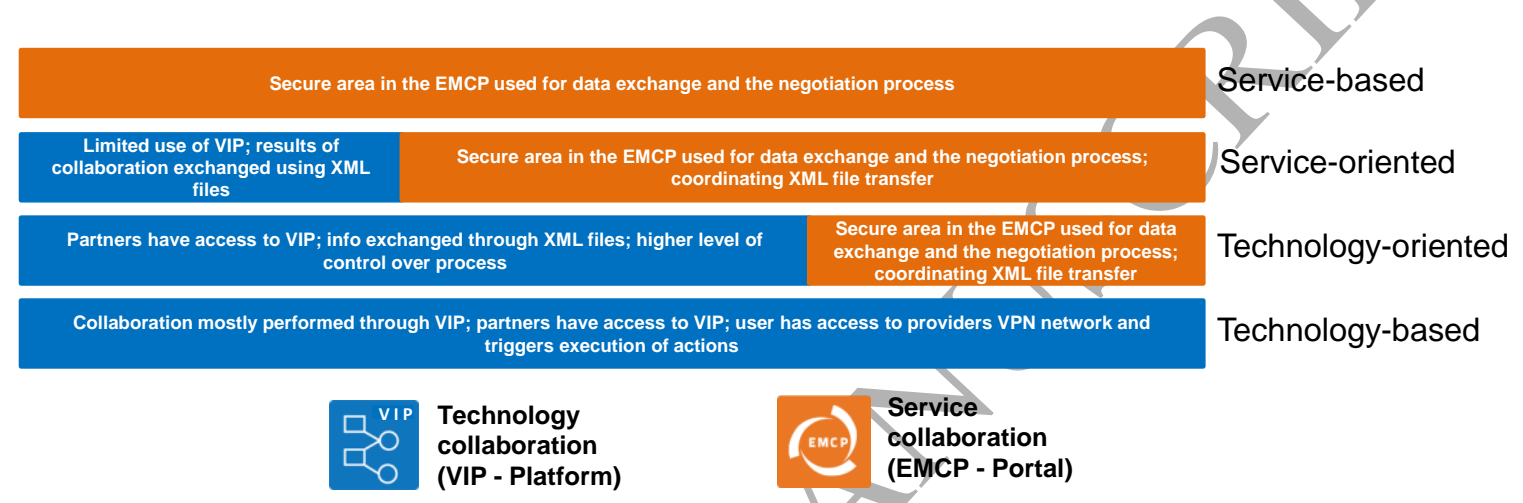

Figure 10. Four levels of collaboration. 


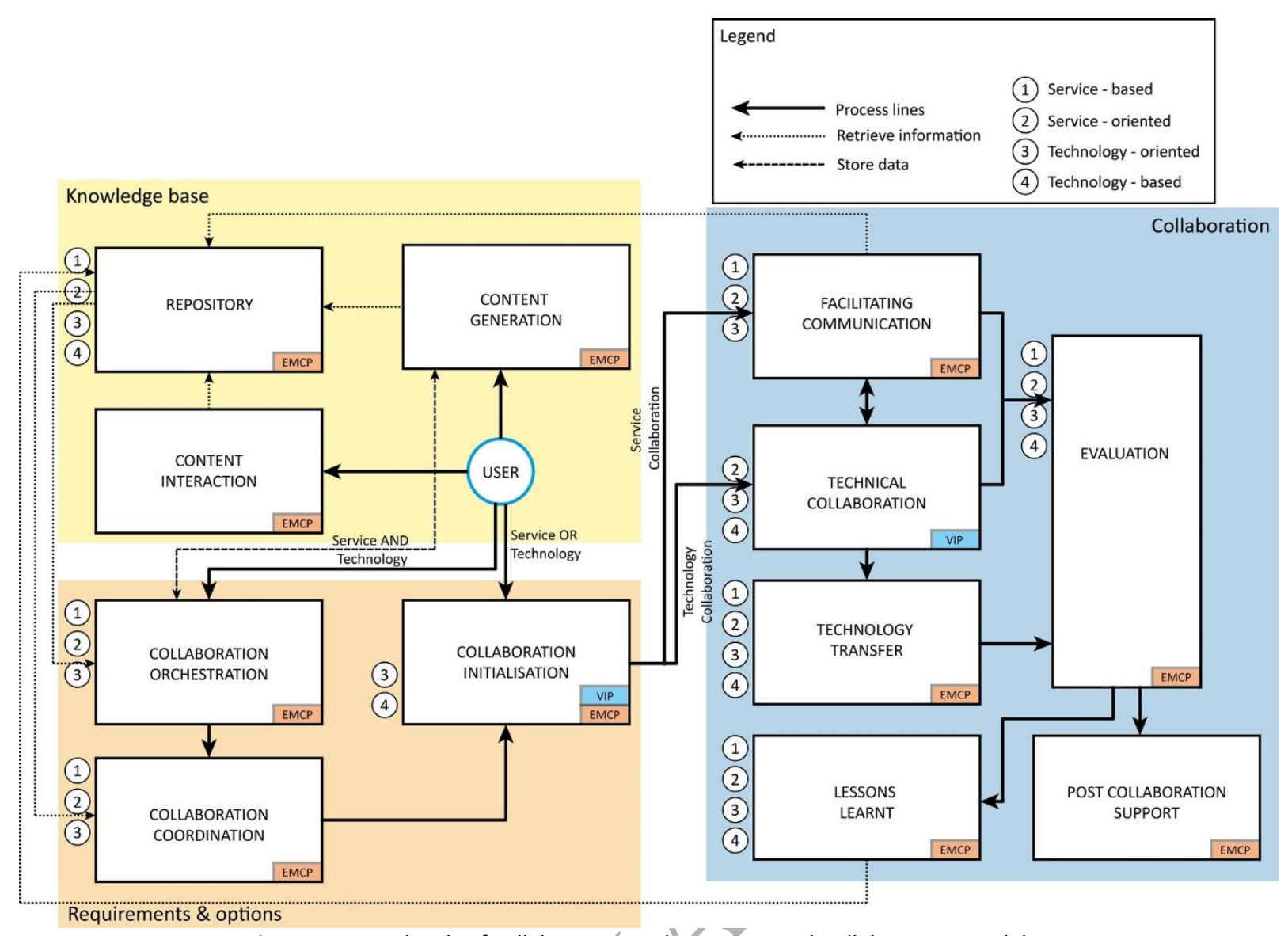

Figure 11. Four levels of collaboration in the Operational Collaboration Model.

Service-oriented and technology-oriented collaboration (Figure 10, Figure 11 denoted with numbers 2 and 3 ) represent two types of the combined collaboration. Both the repository and different design and analysis tools are used, results of the collaboration are exchanged using appropriate technical solutions, and the partners have access to a dedicated secure area used for data exchange and negotiation process. Service-oriented collaboration would focus more on data exchange and negotiation, and the use of design and analysis tools would be limited e.g. one partner provides a calculation using an analysis tool and only the results are transferred to a defined process the second partner has access to. Technology-oriented collaboration reflects a situation where both partners have the same levels of access to design and analysis tools within the defined process and same levels of controloverit.

Within Technology-based collaboration (Figure 10, Figure 11 denoted with number 4), the information in the repository is used only for partner search, while the majority of work is performed using different design and analysis tools. All collaborators would have a defined process to follow, an established way to exchange data, and the ability to trigger execution of actions.

While the modes of collaboration are defined predominantly by the extent to which they use design and analysis tools and/or the repository, any of the levels of collaboration observed could have either top-down or bottom-up approach to collaboration.

\section{Implementation of the OCM}

Three case studies, demonstrating the application of different components of the OCM were defined, developed and implemented by companies within the EuroVIP project to test the validity of the OCM as well as its flexibility in being implemented through tools to support the collaboration process. The VIP provided the main integration software to support technology-oriented collaboration. The VIP was used to remotely activate design and analysis tools allowing the provision 
of a design or analysis service, the exchange of data in a secure environment, and introducing a new business model of service design, implementation and delivery. The EMCP provided support within the case studies for service-oriented collaboration by enabling access to the commonly established knowledge of the European maritime sector requirements and service providers, negotiation and collaboration orchestration facilitation. Figure 12 illustrates sections of the OCM demonstrated in each of the three case studies, denoted with numbers to the left of the boxes displaying different model elements. The collaboration initialisation box is the only one that could be implemented using either EMCP or VIP, depending on the collaboration type, type of data used in it, and the organisations involved in the collaboration and the tools they use. In case study 3 specifically the implementation was done using VIP. While the representation used is the same, the difference between Figure 11 and Figure 12 is that only the elements containing the numbers to the left of the boxes were tested. In Figure 11 the non-numbered boxes might still be a part of the collaboration if required.

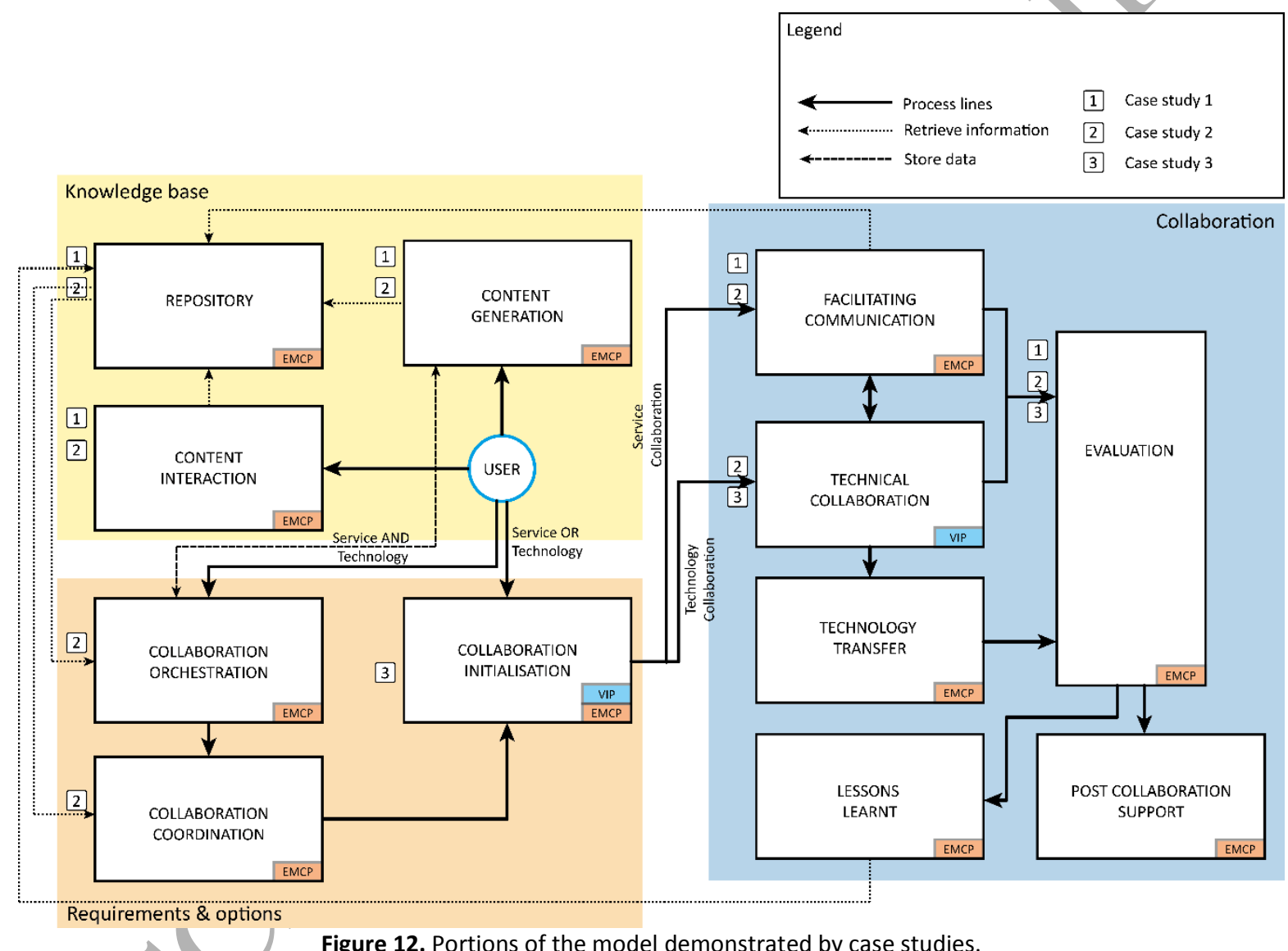

\subsection{Case study 1 - Collaboration in competitive industry conditions}

The first case study, performed by HSVA, was service-based, but demonstrated both service and technology collaboration aspects. The case study was designed to test the OCM application in competitive industry conditions.

HSVA provided a technology called $v$-Shallo, a ship resistance analysis tool, which external companies require to perform certain analysis within their design process. v-Shallo is normally licensed for a fee using traditional marketing efforts. It uses a hardware lock to enforce the licensing, sent via physical mail, installed, set up and tested, which incurs additional cost and time for both HSVA employees and the customer. In the case study a call for collaboration was published using the EMCP, detailing the capabilities of the software and conditions of its use. Communication through the EMCP is, by default, considered confidential, as it is not visible for the general public. After receiving the tenders in response to the published call for collaboration, seven suitable companies, 
with projects that could benefit from v-Shallo application, were identified and given access to the VIP. Details of the collaboration process were negotiated outside of the EMCP, and then the VIP Ticket System was accessed through the EMCP and used to provide the collaboration service. The companies submitted the input for the ship resistance calculations to the VIP, which were performed in-house by HSVA and downloaded the analysis results once complete.

HSVA had reported that elimination of the need to install or configure v-Shallo had brought time savings due to lack of need for accompanied overhead work, and costs savings as the lock shipping and deposit charge were removed. Manual interaction with the v-Shallo code was also notably reduced. The external participants had gained access to a commercial software they had unlimited use of. Both users and service providers' intellectual property rights are protected while the service provision is successfully performed; strengthening each companies market position. Whilst considering the number of companies reached by the call for collaboration, the EMCP fulfilled its purpose, particularly with respect to time available.

\subsection{Case study 2 - Ticket system remote execution}

The second case study performed by SSPA, a towing tank and maritime consultancy company that provides calculation services to external users, was used to test technology-oriented collaboration by allowing external users to submit jobs for computation.

SSPA (with its daughter company FLOWTECH) has developed a variety of flow solvers that they are currently offering to the companies requiring them. In the case study they integrated one of their computation processes into the VIP Ticket System and tested its capabilities. External companies could choose a template they wish to use (different hulls and solvers exist), upload a 3D file describing the hull, define the parameters - the inputs to the command file and then run the execution of the template. A number of templates are available for different types of vessels being analysed.

Once the calculation had finished, three outputs were created: the output containing integrated values and other information; the flow solution; and, a final report containing several contour and vector plots.

If the outputs are within a range that was considered acceptable by SSPA, the execution is considered as completed, the outputs are released to the user and an appropriate number of tickets is deducted from the company's account. If the scripts checking for convergence return an error, the output is still given to the user but no tickets would be charged. The entire system was completely automatic, with the company starting the computation whenever they wish and no interaction is required from SSPA for it to be completed.

The case study was assessed by SSPA and it was concluded that it allowed successful integration of their software in order to offer services to the external companies requiring them. External companies could browse the calculations offered and make the right choice for their needs. SSPA found that the software integration capabilities of the VIP significantly reduced calculation costs, in comparison to the process they would usually employ to provide the same service, allowing them to offer affordable collaboration services to their customers.

\subsection{Case study 3 - Interdepartmental analysis of a ship design}

The third case study was performed at MARIN, to demonstrate an inter-departmental analysis of a ship design using the VIP to integrate different tools within a same process and was a technologybased collaboration. It uses a single base geometry to compute the ship performance according to three separate aspects, which then converge into a single report document.

The multi-disciplinary analysis of a new ship hull demonstrated by the MARIN case study consisted of a number of steps. First the ship was modelled in the geometrical modelling system GMS, followed by hydrodynamic analysis on three aspects: wave resistance (RAPID), seakeeping behaviour (FATIMA), and manoeuvrability (SURSIM). RAOViewer was used to visualise response amplitude operators of ships and structures from any of the MARIN seakeeping or offshore hydrodynamics tools. All tools used had their own visualisation tool and the VIP was used to integrate these tools 
across departments within MARIN into a single process, where inputs and outputs were automatically linked. The report was generated from the visualisations produced by the different tools.

Whilst the VIP had supported the software integration through automating the transfer of information, and helped inter-departmental collaboration, MARIN found that it had neither reduced calculation time and cost, or improved the calculation process and results. The VIP requires low levels of experience to be operated to enable process integration, however it was assessed by MARIN that there was additional functionality required in order to justify wider use.

The first two case studies had reported positive feedback regarding the OCM implementation, software used for it and the effect that had on the working process of the organisations involved. They demonstrated that the OCM implementation is possible and likely beneficial for the companies implementing it. The third case study highlighted functional shortcomings of the VIP rather than omissions within the OCM. While it had successfully implemented the OCM and software, and performed technology collaboration between different departments in a company, the final feedback was that the practical application did not improve the process already used, largely due to the VIP not entirely satisfying the company's requirements.

\section{Discussion}

It was recognised through the industrial definition and design of the case studies that service and technology collaboration do not necessarily have to be separated as most collaborations are a mix of both. The collaboration processes could be further analysed to identify all of the standalone activities present in them as well as their interactions, transforming the "Collaboration" component into a collection of activities arranged in a way that enables companies to elect the most suitable ones for their collaboration needs, without taking into account the type of the collaboration. In the current version of the OCM, a selection of the type of collaboration is necessary, but it could be argued to be harmful to the process, as it may inadvertently limit it to the activities belonging to either service or technology collaboration.

Additionally, the OCM relies on the repository, particularly for communication and recording of collaboration patterns. Populating the repository is done almost exclusively by the companies using it, assuming they will be active and contribute accurate and reliable information regularly. Moderation could ensure the consistency and validity of the information. An automated moderator, while considered, was not implemented in this OCM. In addition, the information should be kept up to date and reflect the inevitable changes in the capabilities of the registered companies in order to best facilitate the construction of new collaborative partnerships. The companies are the owners of the information they contribute. A system that automatically sends queries to an external database and updates the information would technically be a good solution, but might lead to lack of acceptance in the community due to perceived loss of ownership over the information. Data collection and dynamic data management are however not issues exclusive to the OCM, they are a reality of any collaborative process and are something to be aware of during the implementation.

Collaborative partnerships are dynamic and flexible, and thus require occasional redefinition. This might require further consideration in the OCM, as in the current incarnation it does not provide a path back to the "Requirements \& Options" component that would enable a re-composition of the partnership. Additionally, while priorities for collaboration are considered in order to establish the optimal frequency for information exchange between the collaborators, they are only tacitly considered in the rest of the OCM. A more explicit link would make the OCM stronger.

During the population of the repository, the language used is an important issue, and further work on exploration of ontology suitable for the field, or perhaps exploration into if single ontology could be effective is required. Future incarnations of the EMCP may include an element of machine learning and artificial intelligence, which could support ontology creation. 
While the research performed on the needs of the industry was extensive with input from 69 associations, companies and institutions, it focused entirely on the European Maritime enterprises. The results illustrated their needs and collaborative processes within the OCM that could be easily adapted to other industries of similar nature e.g. automotive, aerospace, etc. So far no work had been performed in adapting the OCM to other industries, but during its development the nature of the requirements was considered and the activities within it were generalised, therefore slight adaptations of the OCM will extend its reach to a wider range of industries of similar nature.

The strength of the OCM is that the vision of the collaborative processes it presents is entirely based on the needs of the industry, supported by the theoretical background found in the literature and the practical issues identified from the use of the collaborative tools. These industry needs which were presented in the form of the requirements given in Table 1 were all addressed in the presented $\mathrm{OCM}$, and were implemented through the tools developed for the project. This implementation was tested in the case studies which had covered a large part of the OCM and demonstrated that it comprehensively illustrates a number of collaboration processes tested.

Collaborative engineering is one of the main themes of Industry 4.0, and while this model was not developed specifically to support Industry 4.0, approaches discussed in this paper could be used to inform future Industry 4.0 research, particularly that focused on collaboration, cooperation, communication and integration of data.

\section{Conclusion}

The Operational Collaboration Model is the first model to consider the needs of practitioners, findings from academic literature and requirements gained by observing practical issues encountered while collaborating using software support. It aims to provide guidance and support to organisations collaborating across different fields, often geographically distributed and likely possessing different working cultures, and ensure that they engage in collaboration processes that will bring competitive advantage for everyone involved. While there is still space for improvement of the OCM, particularly once a more extensive implementation takes place, the case studies have demonstrated that the OCM does abstract the collaboration in the maritime sector accurately, and that it proposes a number of innovative solutions. Companies were able to set up and execute their collaboration process, while completely controlling the availability and accessibility of both technical and collaborative information. The model provides flexibility in the use of tools and their integration within the collaborative endeavour. It also provides guidance in terms of required collaborative steps and consideration of key collaborative activities. Interdependencies between different aspects of a collaborative process are considered and supported by both the model and the tools used for its implementation. The user evaluation of the model was positive and all three case studies were successfully completed.

The OCM was developed and evaluated in the maritime sector, but the manner in which it was built ensures it can be extended to any sector requiring collaborative work with extensive data sharing. The model architecture ensures that collaboration modes can be tailored to the needs of the companies engaging in the collaboration. Similarly, the model, although general and applicable to a variety of sectors as is, could be tailored to fit the needs of a different sector more closely.

\section{Acknowledgements}

The authors would like to acknowledge the funding received to enable this research to be undertaken. The EuroVIP project was funded by the European Commission (grant number SCSO-GA2011-266054), as a part of the Seventh Framework Programme, Coordination and support action; THEME SST.2010.6-1. "Towards improved technology transfers". The opinions are those of the authors and should not be construed to represent the views of the EuroVIP consortium. 


\section{References}

[1] A. C. Marquez, C. Bianchi, and J. N. D. Gupta, "Operational and financial effectiveness of ecollaboration tools in supply chain integration," European Journal of Operational Research, vol. 159, pp. 348-363, 2004.

[2] H. Zou and T. Yu, "The research on decision model of supply chain collaboration management," in 2008 International Conference on Wireless Communications, Networking and Mobile Computing, WiCOM 2008, October 12, 2008 - October 14, 2008, Dalian, China, 2008, pp. Wuhan University, China; Dalian University of Technology, China; IEEE Antennas and Propagation Society; Scientific Research Publishing, USA; IEEE Communications Society.

[3] G. Kumar and R. N. Banerjee, "Collaboration in supply chain," International Journal of Productivity and Performance Management, vol. 61, pp. 897-918, 2012

2012-11-10 2012.

[4] Q. Zhang, "Research on Intelligent Management Model in Distribution Service System: Based on Collaboration FPS Management," Contemporary Logistics, pp. 111-116, Sep 2011

2013-05-24 2011.

[5] K. Z. Bijon, R. Sandhu, and R. Krishnan, "A group-centric model for collaboration with expedient insiders in multilevel systems," in 2012 13th International Conference on Collaboration Technologies and Systems, CTS 2012, May 21, 2012 - May 25, 2012, Denver, CO, United states, 2012, pp. 419-426.

[6] T. Takahashi, Y. Kadobayashi, and K. Nakao, "Toward global cybersecurity collaboration: Cybersecurity operation activity model," in Kaleidoscope 2011: The Fully Networked Human?-Innovations for Future Networks and Services (K-2011), Proceedings of ITU, 2011, pp. 1-8.

[7] E. P. Andert Jr and D. Morgan, "Collaborative virtual prototyping and test," Naval Engineers Journal, vol. 110, pp. 17-23, 1998.

[8] R. Bencic, M. Milanovic, G. ikic, and M. Bistricic, "Multi-platform collaboration tool for ship design and production," in International Conference on Computer Applications in Shipbuilding 2013, ICCAS 2013, September 24, 2013 - September 26, 2013, Busan, Korea, Republic of, 2013, pp. 135-142.

[9] W. Zhang and C. Luttervelt, "On the support of design process management in integrated design environment," CIRP Annals-Manufacturing Technology, vol. 44, pp. 105-108, 1995.

[10] D. Zhang, J. An, and Z. Cheng, "Collaboration E-business model for the dealer," in 2006 IEEE International Conference on Service Operations and Logistics, and Informatics, SOLI 2006, June 21, 2006 - June 23, 2006, Shanghai, China, 2006, pp. 878-882.

[11] J. Jiang, V. Dignum, Y.-H. Tan, and S. Overbeek, "A context-aware inter-organizational collaboration model applied to international trade," in International Conference on Electronic Government, 2011, pp. 308-319.

[12] D. Oppenheim, S. Bagheri, K. Ratakonda, and Y.-M. Chee, "Agility of enterprise operations across distributed organizations: A model of cross enterprise collaboration," in 2011 Annual SRII Global Conference, SRII 2011, March 30, 2011 - April 2, 2011, San Jose, CA, United states, 2011, pp. 154-162.

[13] L. Limonad, L. R. Varshney, D. V. Oppenheim, E. Fein, P. Soffer, Y. Wand, et al., "The waasabe model: Marrying waas and business-entities to support cross-organization collaboration," in 2012 Annual SRII Global Conference, SRII 2012, July 24, 2012 - July 27, 2012, San Jose, CA, United states, 2012, pp. 303-312.

[14] S. G. Hutchins, A. Bordetsky, T. Kendall, and M. Garrity, "Evaluating a model of team collaboration via analysis of team communications," in 51st Annual Meeting of the Human Factors and Ergonomics Society, HFES 2007, October 1, 2007 - October 5, 2007, Baltimore, MD, United states, 2007, pp. 415-419. 
[15] S. G. Hutchins and T. Kendall, "Patterns of team collaboration employed to solve unique problems," in 52nd Human Factors and Ergonomics Society Annual Meeting, HFES 2008, September 22, 2008 - September 26, 2008, New York, NY, United states, 2008, pp. 478-482.

[16] L. Chi and C. W. Holsapple, "Understanding computer-mediated interorganizational collaboration: a model and framework," Journal of Knowledge Management, vol. 9, pp. 5375,2005

2014-05-25 2005.

[17] S. Philbin, "Process model for university-industry research collaboration," European Journal of Innovation Management, vol. 11, pp. 488-521, 2008

2013-07-17 2008.

[18] S. P. Hocevar, E. Jansen, and G. F. Thomas, "Inter-Organizational Collaboration: Addressing the Challenge," Homeland Security Affairs, vol. 7, 2011

2013-01-24 2011.

[19] H. Xu, L. Shen, X. Xie, Q. Wang, Y. Liu, and K. Wang, "Research on the business operation model based on Semantic Web service and MAS," in 2008 International Conference on Computational Intelligence and Security, CIS 2008, December 13, 2008 -December 17, 2008, Suzhou, China, 2008, pp. 71-75.

[20] R. Anderl, J. Racler, and D. Volz, "Modeling global product development projects - The idea of the product collaboration information model," in 16th European Concurrent Engineering Conference, ECEC 2009 and the 6th Future Business Technology Conference, FUBUTEC 2009, April 15, 2009 - April 17, 2009, Bruges, Belgium, 2009, pp. 99-104.

[21] A. Lau, T. Fischer, M. Hirsch, and H. Matheis, "SmartNet collaboration model - A framework for collaborative development and production," in 2012 18th International Conference on Engineering, Technology and Innovation, ICE 2012, June 18, 2012 - June 20, 2012, Munich, Germany, 2012.

[22] A. M. Thomson and J. L. Perry, "Collaboration processes: Inside the black box," Public administration review, vol. 66, pp. 20-32, 2006.

[23] A. Larsson, Å. Ericson, T. Larsson, O. Isaksson, and M. Bertoni, "Engineering 2.0: exploring lightweight technologies for the virtual enterprise," in From CSCW to Web 2.0: European Developments in Collaborative Design, ed: Springer, 2010, pp. 173-191.

[24] K. Meyer and M. Thieme, "Activating the Innovation Potential of SME: The Bottom-UpApproach," in ISSS/BPSC, 2010, pp. 3-16.

[25] M. Wulan, X. Dai, and K. Popplewell, "Collaboration knowledge ontologies to support knowledge management and sharing in Virtual Organisations," in Enterprise Interoperability IV, ed: Springer, 2010, pp. 179-186.

[26] R. Cagliano, V. Chiesa, and R. Manzini, "Differences and similarities in managing technological collaborations in research, development and manufacturing: a case study," Journal of engineering and technology management, vol. 17, pp. 193-224, 2000.

[27] I. Hamburg and M. Marin, "Facilitating knowledge transfer to drive innovation in SMEs," in Innovation through Knowledge Transfer, ed: Springer, 2010, pp. 167-177.

[28] M. Zimmermann, R. Bronsart, and K. Stenzel, "Knowledge based engineering methods for ship structural design," in 12th International Conference on Computer Applications in Shipbuilding (ICCAS), 2005, pp. 23-26.

[29] I. Horváth, "Recent developments in computer supported cooperative work in design: from group collaboration through global connectivity to informing apobetics," in Computer Supported Cooperative Work in Design (CSCWD), 2012 IEEE 16th International Conference on, 2012, pp. 2-13.

[30] K. Popplewell, N. Stojanovic, A. Abecker, D. Apostolou, G. Mentzas, and J. Harding, "Supporting adaptive enterprise collaboration through semantic knowledge services," in Enterprise Interoperability III, ed: Springer, 2008, pp. 381-393. 
[31] F. E. H. Tay and A. Roy, "CyberCAD: a collaborative approach in 3D-CAD technology in a multimedia-supported environment," Computers in Industry, vol. 52, pp. 127-145, 2003.

[32] J. Kim, S. Hong, J. Min, and H. Lee, "Antecedents of application service continuance: A synthesis of satisfaction and trust," Expert Systems with Applications, vol. 38, pp. 9530-9542, 2011.

[33] D. Garrison, "Communities of inquiry in online learning," Encyclopedia of distance learning, pp. 352-355, 2009.

[34] B. Swoboda, M. Meierer, T. Foscht, and D. Morschett, "International SME Alliances: The Impact of Alliance Building and Configurational Fit on Success," Long Range Planning, vol. 44, pp. 271-288, 2011.

[35] D. Gambetta, "Trust: Making and breaking cooperative relations," 1988.

[36] J. Tounsi, G. Habchi, J. Boissière, and S. Azaiez, "A multi-agent knowledge model for SMEs mechatronic supply chains," Journal of Intelligent Manufacturing, vol. 23, pp. 2647-2665, 2012.

[37] R. Swarnkar, A. K. Choudhary, J. A. Harding, B. P. Das, and R. Young, "A framework for collaboration moderator services to support knowledge based collaboration," Journal of Intelligent Manufacturing, vol. 23, pp. 2003-2023, 2012.

[38] H. Thimm and K. Boye Rasmussen, "An information support service for moderators of SME company networks," Management Research News, vol. 32, pp. 846-857, 2009.

[39] D. Stokic, A. T. Correia, and C. Grama, "Tools for designing collaborative working environments in manufacturing industry," in Complex Systems Concurrent Engineering, ed: Springer, 2007, pp. 613-620.

[40] A. Kipp, L. Schubert, M. Assel, and T. Fernando, "Dynamism and Data Management in Distributed, Collaborative Working Environments," in Proc. 8th International Conference on the Design of Cooperative Systems, 2008, pp. 16-22.

[41] E. Ermilova and H. Afsarmanesh, "Competency Modeling Targeted on Promotion of Organizations Towards VO Involvement," in Pervasive Collaborative Networks. vol. 283, L. Camarinha-Matos and W. Picard, Eds., ed: Springer US, 2008, pp. 3-14.

[42] H. Afsarmanesh, L. M. Camarinha-Matos, and S. S. Msanjila, "On management of 2nd generation virtual organizations breeding environments," Annual Reviews in Control, vol. 33, pp. 209-219, 2009.

[43] M. Germani, M. Mandolini, M. Mengoni, and M. Peruzzini, "Platform to support dynamic collaborative design processes in virtual enterprises," International Journal of Computer Integrated Manufacturing, vol. 26, pp. 1003-1020, 2013.

[44] Anonymous, Details omitted for double-blind reviewing, 2012. 